\title{
ОСОБЕННОСТИ ОБУЧЕНИЯ РУССКОЙ ВОКАЛЬНОЙ ШКОЛЫ И ЕЕ ОТРАЖЕНИЕ В ПЕДАГОГИЧЕСКОЙ ПРАКТИКЕ КИТАЙСКИХ ПЕДАГОГИЧЕСКИХ ВУЗОВ
}

\section{FEATURES OF TEACHING RUSSIAN VOCAL SCHOOLS AND ITS REFLECTION IN THE TEACHING PRACTICE OF CHINESE PEDAGOGICAL UNIVERSITIES}

Bao Nuan

Summary: Until 2005, the official Chinese educational system focused mainly on the practice of teaching Western and Chinese classical music, but now much attention is paid to the experience of the Russian vocal school. Russian vocal education has long been listed as one of the best and leading in the world, along with Italian, which allows students to demonstrate high creative achievements.

Traditional and innovative Russian methods are successfully implemented in Chinese pedagogical universities, both by attracting teachers from Russia, and by using the Russian system of teaching vocal skills as a fundamental component of teaching methods in Chinese conservatories. The multicultural approach, which integrates the systems of vocal education and educational methodological programs of educational facilities in Russia and China, is able to maximize and optimize the pedagogical potential and models for the development of vocal abilities of students of Chinese classical music institutions of higher education. Familiarity with the musical culture of different countries in the light of targeted vocal training is an effective means for developing the musical spectrum of knowledge of Chinese students.

Keywords: music, Russian vocal school, Chinese vocal school, vocal performance, education of Chinese students, singing pedagogy, higher education.

\author{
Бао Нуань \\ Аспирант, ФГБОУ ВО «Российский государственный \\ педагогический университет им. А.И. Герцена», \\ г. Санкт-Петербург \\ baonuan@foxmail.com
}

Аннотация: Вплоть до 2005 года официальная китайская образовательная система ориентировалась преимущественно на практику преподавания западной и китайской классической музыки, однако, в настоящее время большое внимание стало уделяться опыту русской вокальной школы. Российское вокальное образование давно котируется как одно из лучших и ведущих в мире, наравне с итальянским, что позволяет обучающимся демонстрировать высокие творческие достижения.

Традиционные и инновационные российские методики успешно внедряются в китайских педагогических вузах, как посредством привлечения преподавателей из России, так и путём использования российской системы обучения вокальному мастерству в качестве фундаментообразующего компонента педагогических методик в китайских консерваториях.

Поликультурный подход, интегрирующий в себе системы вокального воспитания и учебные методические программы средств обучения России и Китая, способен эффективизировать и оптимизировать педагогический потенциал и модели развития вокальных способностей обучающихся китайских классических музыкальных высших учебных заведений.

Знакомство с музыкальной культурой разных стран в свете целенаправленного обучения вокалу является эффективным средством для развития музыкального спектра знаний обучающихся Китая.

Ключевые слова: музыка, русская вокальная школа, китайская вокальная школа, вокальное исполнение, обучение китайских студентов, педагогика пения, высшее образование.
B Китае музыкальное образование является важным компонентом всестороннего становления личности человека и часто используется для духовного и интеллектуального самосовершенствования людей в контексте «изучение музыки с целью изучения музыки» [11, р. 201]. Расширение представлений о вокальных направлениях, стилях, жанрах в конгломерате китайской и русской культур дает возможность сформировать более углубленные навыки и знания о высоком искусстве и повысить уровень эстетического восприятия с упором на опыт эталонных школ.

В реформировании вокального образования Китая учёные дифференцируют четыре периода: II тыс. до н.э. - начало XX в. - подготовка вокалистов на традиционной основе; начало XXв. - 1949 г. - обучение вокалистов по европейской академической системе [5 с. 54]; с 1949 - 1976 гг. обучение вокальному исполнительству по советской системе, с 1976 г. до настоящего времени - интегрирование лучших модернизированных методов и методик в системе высшего музыкального образования исполнительства разных стран [6, с. 13].

Говоря о российском музыкальном образовании, следует отметить, что в XIX веке деятельность многих выдающихся европейских исполнителей, переехавших в Россию, стала источником становления русской вокальной школы. Был осуществлен синтез европейской и русской традиций, что явилось основой воспитания певцов Санкт-Петербургской и Московской консерваторий. Вокальная педагогика в России, главным образом, опиралась на лучшие достижения итальянской и француз- 
ской школ. Лучшие из иностранных педагогов восприняли особенности русской классической музыки и могли творчески сочетать эти стилевые особенности с итальянской певческой культурой [10, р. 286]. Для начинающих, молодых педагогов и вокалистов-исполнителей сегодня основополагающими до сих пор являются произведения М.И. Глинки, А.Е. Варламова и Г. Ниссен-Саломан.

Петербургская и Московская вокальные школы попрежнему остаются наиболее значимыми в истории не только российского, но и китайского вокального образования. Согласно исследованиям Ч. Сюецзюнь и Н.В. Бычковой, существенный вклад в развитие высшей китайской школы академического пения внесли Ф.И. Шаляпин и В.Г. Шушлин (солист Мариинского театра). В.Г. Шушлин (бас) с 1924 по 1956 гг. преподавал в Шанхайской консерватории и в других вузах, а его педагогика и певческий стиль опирались на технику бельканто [4] (bel canto, а именно - «плотную кантилену, обилие украшений, сложных импровизаций и мелкую колоратурную технику» [2, c. 15]).

С конца XX в. у китайских обучающихся появилось гораздо больше возможностей выезжать на обучение за границу, что позволило на фоне возрастающего интереса педагогов к особенностям обучения русской вокальной школы, организовать культурный обмен и оптимизировать процесс обучения вокалу китайских студентов. Сегодня русская национальная высшая певческая школа предоставляет большой потенциал для обогащения китайской вокальной педагогики, включая формирование вокально-исполнительских возможностей [2, с. 3 - 4].

Современные исследователи (S.A. Konovalova, T. Zhang, D. Sun, 2020) отмечают, что вокальное исполнение способствует формированию музыкальной культуры китайских студентов. Сегодня данный вид исполнительства выступает в роли одного из центральных направлений в музыкальном образовании на разных уровнях образовательного процесса: от детских вокальных школ до обучения в высших учебных заведениях, в которых разнообразие подходов и методологий огромно и вариативно. Современная педагогика опирается на традиции, сложившиеся в русской и итальянской вокальных школах, и внедряет модернизированные методики преподавания вокального мастерства обучающимся. А именно, на уровне высшего учебного заведения современная вокальная китайская педагогика включает традиционные подходы к преподаванию, основанные на русской и итальянской вокальных школах, а также современные методики, направленные на формирование технического мастерства популярной и джазовой музыки, непосредственно упражнения, направленные на развитие чувства ритма по методике А. Карягиной [9, р. 32].

Говоря о традиционном подходе к обучению, следует отметить, что в процессе формирования навыков пения преподаватели эстрадного вокала используют подходы из педагогики академического вокала [9, р. 32]. Развитие вокальных навыков и эстрадных техник исполнения студентов китайских консерваторий возможно путем включения в учебный процесс современных методик, используемых как в академическом, так и в эстрадном вокалах.

Исходя из педагогических наблюдений Цзян Шанжун (2019) за деятельностью преподавательского состава вокальной кафедры музыкального искусства, учёный пришел к выводу, что русская высшая школа для китайских обучающихся сегодня обладает определенной яркой спецификой, своеобразие которой заключается в том, что она опирается на древнейшие песенные традиции, характерную для россиян «народную» распевность (в т.ч. legato, ориентированное на обучение кантиленному пению), делает упор на простую, но выразительную плавную мелодию, акцентируя при этом внимание на поэтической составляющей вокальных произведений и слове (смысловом контексте музыкального произведения), в то же время, уделяя большое внимание подготовке профессиональных оперных певцов с учётом традиций итальянской школы [5, с. 44]. «Звукообразование русской певческой школы напрямую связано с итальянской школой и направлено на исполнение европейской и мировой вокальной музыки посредством умелой работы всего голосового аппарата» [2, с. 3 - 4].

В научном исследовании Яньтао Цуй (2020) подчеркнуто, что в итальянской школе большая роль отводится демонстрации вокальных данных, пассажей и огромного регистра, полётности высоких нот, а также инструментальной методике развития вокального голоса в свойственной для инструментального звучания тембровой окраске, тогда как для российских вокалистов чрезмерно важна смыслообразующая составляющая пения «наполнить содержанием исполняемого музыкального произведения логикой сценической ситуации» [7, с. 14].

По мнению китайских педагогов, еще одной важной отличительной особенностью русской вокальной школы является обращение к фольклору (например, ансамбль имени Д. Покровского [6, с. 18]) и воспроизводство традиций церковного пения, в то время как для Китая характерно представление о вокале, как о порождении Вселенной (с упором на гилозоизм), что обусловило в музыке множество коррелятов [5, с. 59].

Исходя из концепций вышепредставленных ученых, можно сделать вывод, что русская и итальянская высшие вокальные школы корреспондируют друг другу. С учетом принципов русско-итальянской педагогики по формированию вокальных данных студентов, следует подчеркнуть их дуальность с такими вокальными 
структурообразующими компонентами в рамках традиционной китайской оперы, как: «орнаментальная, интонационно и ритмически прихотливая мелодия, высокие регистры, изложение музыкального материала в специфической тональной системе - пентатонике» [6, с. 18].

Что характерно, занятия такого формата, где в роли концептообразующего звена выступает русско-китайская педагогика, являются эффективным средством формирования у обучающихся умения говорить и исполнять вокальные произведения на русском языке. Как отмечают педагоги-вокалисты и логопеды, в процессе вокализации развитие русскоязычной артикуляции происходит гораздо быстрее и легче [9, р. 33]. Исходя из исследований Лу Хуачжао (2018), полифоническая взаимосвязь вокальной музыки и фонетики китайской речи, а также включение в вокально-образовательный процесс русской речи (по методике С.А. Коноваловой [9]), обусловило высокий потенциал вокальной музыки для китайских педагогов (и китайского социума), в отличие от инструментальной [2, с. 79]. Непосредственно русским педагогом С.А. Коноваловой был разработан комплекс речевых и вокальных упражнений для повышения уровня вокального исполнения на русском языке сквозь призму формирования русскоязычной артикуляции у студентов из Китая [9, р. 32].

Обучение китайских студентов вокалу способствует формированию певческих навыков на основе современных методик: «инновационные» и традиционные методы российских педагогов, используемых в Китае, включают в себя четыре базовых аспекта:

1. формирование вокального мастерства студентов на основе резонансной техники пения, которая опирается на индивидуальные способности вокалиста, физиологические особенности его тела и выносливость;

2. интерактивность цифровых технологий в вокальной подготовке китайских студентов;

3. «экология оперного пения»;

4. метод внутреннего (мысленного) пения.

Предлагаем к более подробному рассмотрению каждый из вышеперечисленных аспектов:

1. Основателем резонансной теории, положившей начало формированию вокального мастерства, является В.П. Морозов. Ученый, аккумулировав и проанализировав педагогический опыт преподавания вокала за последние 400 лет, первым обратил внимание на целесообразность учета психофизиологии пения и биофизических (биоакустических) свойств человеческого тела, таким образом, придя к выводу, что фундаментом успешного обучения вокалу являются дыхание и резонаторность (передача силы звука, фонетические свойства вокальной речи, тембр голоса и пр.)

\section{$[7$, c. 16].}

Говоря о дыхании в контексте вокально-педагогических традиций, стоит отметить, что согласно мнению многих российских авторов методик обучения пению, одним из основных вокальноисполнительских навыков является вдох. При работе с этим навыком на вокальных занятиях актуально использовать упражнения из методик А.Н. Стрельниковой и И.В. Цукановой, модернизированные посредством дыхательной гимнастики С.А. Коноваловой. Например, по мнению китайских студентов С.А. Коноваловой, самым любимым и эффективным упражнением в указанной гимнастике является «музыкальное дыхание». Суть этого занятия заключается в том, что обучающийся дышит в соответствии с музыкой, произнося фразу с использованием различных типов дыхания. Это упражнение выполняется как статически, так и в движении в соответствии с музыкой [9, р. 34].

2. Эффективизации процесса обучения вокальному мастерству способствуют цифровые технологии. S.A. Konovalova, T. Zhang, D. Sun (2020) привели в пример такие технологии, как смартфоны и социальные сети, позволяющие оптимизировать процесс обучения вокалу китайских студентов. Смартфоны были использованы для прослушивания изучаемых музыкальных произведений и исполнительского мастерства самих китайских обучающихся; в социальной сети WeChat, был создан групповой чат для общения студентов и преподавателей, который служил для передачи учебно-методического материала; публикации ссылок на Интернет-источники, содержащие такую информацию на китайском языке, как историография джаза и биографии исполнителей джазового вокала. Следующие аудиозаписи известных вокальных исполнителей были предоставлены студентам для прослушивания через музыкальное приложение: Ella Fitzgerald, Louis Armstrong, Frank Sinatra, Sarah Vaughan, Miles Davis Quinte и др. Прослушивание дополнительного учебного материала посредством Интернет-ресурсов и гаджетов, а также в живом исполнении на концертах джазовой и эстрадной музыки, согласно полученным результатам исследователей, мотивировало студентов осваивать навыки пения более скрупулёзно. При этом китайские обучающиеся лично предложили сделать сравнительную характеристику китайской, русской и западноевропейской современной популярной вокальной музыки [9, с. 34].

3. «Экология оперного пения" интерпретируется Цзян Шанжуном (2018), как выявление, развитие и сохранение ярких природных вокальных данных студентов музыкальных вузов, обладающих потенциалом оперного пения; организация усло- 
вий и реализация вокальных способностей в процессе оперного пения [6, с. 11]. «Экологическое оперное пение» - это дифференцированный подход, включающий в себя междисциплинарный образовательный процесс: изучение «исторических, культурологических, психологических и физиологических аспектов вокальной педагогики» [6, с. 18], общемузыкальное развитие: формирование общих музыкальных способностей, слушательского опыта; профессиональная подготовка; спортивное развитие.

4. Одним из наиболее эффективных методов работы в вокальных классах является метод внутреннего (мысленного) пения, активизирующий внутренние представления и «слуховое внимание, направленное на восприятие и запоминание звукового эталона. Мнимое пение учит внутренне сосредоточиться, предохраняет голос от переутомления» [3, с. 225; 5, с. 73]. Данный метод обучения предполагает «пропевание» текстов «песни внутренним голосом на основе ярких слуховых представлений» [1, с. 122].

\section{Выво $\triangle$}

Взаимообусловленное влияние китайской и россий- ской школ с конца XX в. определено возможностями студентов выезжать в обозначенные страны (КНР и Россия) с целью получения профессионального вокального образования, а также в связи активным творческим сотрудничеством России и КНР с европейскими музыкантами, что объединяет методическое ядро вокальной педагогики российской и китайской школ в контексте высшего образования, делая для китайских студентов понимание и осмысление учебного материала русской вокальной школы понятным и эффективно усвояемым. Среди основных и общих специфических черт систем вокального воспитания в педагогических вузах России и Китая, целесообразно назвать обращение к итальянским традициям: российская вокальная педагогика тесно коррелирует с итальянской певческой культурой, в особенности, по технике бельканто, что импонирует китайской высшей школе вокала. В классическую методику преподавания вокала, базирующуюся на педагогических принципах русской музыкальной школы, в китайских вузах интегрируются традиционные методы («экология оперного пения» и «метод внутреннего (мысленного) пения») и инновационные подходы и технологии, в частности, при вокальной подготовке китайских студентов развиваются принципы формирования вокального мастерства на основе резонансной техники пения и с использованием различных цифровых устройств.

\section{ЛИТЕРАТУРА}

1. Куко, С.С. Индивидуально-ориентированная педагогическая технология подготовки студентов эстрадно-джазового вокала к концертной деятельности: дисс. ... кандидата педагогических наук: 13.00.02 / Куко Светлана Сергеевна; [Место защиты: Армавирский государственный педагогический университет]. - Белгород, 2019. - 239 с.

2. Лу Хуачжао. Педагогические условия развития вокально-исполнительского потенциала китайских студентов в образовательном процессе вуза: дисс. ... кандидата педагогических наук: 13.00.08 / Лу Хуачжао; [Место защиты: Воронеж. гос. ун-т]. - Воронеж, 2018. - 191 с.

3. Сладкопевец, Р.В. Методы вокального обучения и практика бельканто в классе сольного пения / Р.В. Сладкопеыец // Вестник МГУкИ. 2014. №1 (57). - С. $221-226$.

4. юецзюнь, Ч. Развитие китайской национальной вокальной школы в контексте традиций западноевропейского академического вокального искусства [Электронный ресурс] / Ч. Сюецзюнь, Н.В. Бычковой // URL: https://elib.bspu.by/bitstream/doc/30983/1/\%D0\%91\%D1\%8B\%D1\%87\%D0\%BA\%D0\%BE\%D0 \%B2\%D0\%B0.pdf. Дата обращения: 25.06.2020.

5. Цзян Шанжун. Педагогический потенциал взаимодействия систем вокального воспитания студентов в музыкально-педагогических вузах России и Китая: дисс. ... кандидата педагогических наук: 13.00.02 / Цзян Шанжун; [Место защиты: Моск. гор. пед. ун-т]. - Москва, 2019. - 195 с.

6. Цзян Шанжун. Педагогический потенциал взаимодействия систем вокального воспитания студентов в музыкально-педагогических вузах России и Китая: автореферат дисс. ... кандидата педагогических наук: 13.00.02 / Цзян Шанжун; [Место защиты: Моск. гор. пед. ун-т]. - Москва, 2019. - 28 с.

7. Цуй Яньтао. Формирование вокального голоса обучающегося на основе резонансной техники пения: автореферат дисс. ... кандидата педагогических наук: 13.00.02 / Цуй Яньтао; [Место защиты: ГАОУ ВО ГМ «Московский городской педагогический университет»]. - Москва, 2020. - 26 с.

8. Яо Вэй. Подготовка специалистов вокального искусства в системах высшего музыкального образования Китая и России: дисс. ... кандидата педагогических наук: 13.00.01 / Яо Вэй; [Место защиты: Волгогр. гос. соц.-пед. ун-т]. - Астрахань, 2015. - 196 с.

9. Konovalova, S.A. (2020) Digital Technologies in Vocal Training of Chinese Students in Russian Higher Education Institutions / S.A. Konovalova, T. Zhang, D. Sun // Advances in Social Science, Education and Humanities Research, Vol. 437. - Pp. 32 - 36.

10. Martynova, Y., Martynov, D., \& Sukhova, A. (2018). Theoretical Principles of the Russian Vocal School in the 19th Century. Journal of History Culture and Art Research, 7(4), 285-292.

11. Yuhang Zhang. A Comparative study of vocal music education between China and the United States / Yuhang Zhang // Advances in Educational Technology and Psychology (2018) 2: 200-204. 